\title{
Long-term outcome of pulmonary function in farmer's lung: a 14 year follow-up with matched controls
}

\author{
R. Erkinjuntti-Pekkanen*, J.I. Kokkarinen*, H.O. Tukiainen*, \\ J. Pekkanen**, K. Husman+, E.O. Terho++
}

Long-term outcome of pulmonary function in farmer's lung: a 14 year follow-up with matched controls. R. Erkinjuntti-Pekkanen, J.I. Kokkarinen, H.O. Tukiainen, J. Pekkanen, K. Husman, E.O. Terho. @ERS Journals Ltd 1997.

ABSTRACT: The long-term outcome of pulmonary function was evaluated in farmer's lung (FL) patients compared to representative control farmers. This is, to our knowledge, the first such study which has included a control group.

Clinical examinations were conducted in 89 FL patients and 84 control farmers, matched by age, sex, and smoking habits. The mean time after the first diagnosed episode of FL was 14 yrs.

The mean transfer factor of the lung for carbon monoxide $\left(T_{\mathrm{L}}, \mathrm{CO}\right)$ was on average $12 \%$ lower $(\mathbf{p}<\mathbf{0 . 0 0 1})$ in FL patients compared to control farmers. In spirometry, the mean maximum expiratory flow at $50 \%$ of vital capacity (MEF50) was lower $(p=0.08)$ in FL patients but there were no differences in mean vital capacity (VC) or forced expiratory volume in one second (FEV1) between FL patients and control farmers. However, airway obstruction, defined as an FEV1/VC less than $88 \%$ of predicted, was more common in FL patients than in control farmers (33 versus 17\%; $\mathrm{p}=0.02$ ). Patients who had had recurrent episodes of FL had a significantly lower mean $T_{\mathrm{L}}$,co compared to those FL patients who had experienced only a single episode.

In conclusion, impairment of the pulmonary transfer factor is the most important long-term consequence of farmer's lung. However, farmer's lung may also lead to development of airway obstruction.

Eur Respir J 1997; 10: 2046-2050.
*Dept of Pulmonary Diseases, Kuopio University Hospital, Kuopio, Finland. **Dept of Environmental Epidemiology, National Public Health Institute, Kuopio, Finland. +Kuopio Regional Institute of Occupational Health, Kuopio, Finland. ++Dept of the Diseases of the Chest, Turku University Hospital, Turku, Finland.

Correspondence: R. Erkinjuntti-Pekkanen Dept of Pulmonary Diseases Kuopio University Hospital FIN-70210 Kuopio Finland

Keywords: Case-control study farmer's lung pulmonary function

Received: June 131996 Accepted after revision May 311997

Supported by a grant from Farmers' Social Insurance Institution of Finland.
Recovery of pulmonary function after an acute episode of farmer's lung (FL) may take years, especially with respect to the pulmonary transfer factor [1]. Some patients remain with permanent defects in ventilatory function, impairment of pulmonary gas transfer or hypoxaemia [2-4].

Farm work in general is known to be a risk factor for chronic bronchitis and impaired pulmonary function [58]. However, no previous study on the long-term outcome of farmer's lung has included healthy farmers as a control group. Therefore, we conducted a case-control study comparing the pulmonary function of $89 \mathrm{FL}$ patients, a mean of 14 yrs after the diagnosis of the disease, with a representative group of 84 control farmers matched for age, sex and smoking habits.

\section{Methods}

\section{Study population}

Of the $101 \mathrm{FL}$ patients included in a previous study on farmer's lung [1], 97 who were still alive were asked to participate in the present study. In the four patients who had died, the causes of death (coronary artery dis- ease in two, malignancy in one and pneumonia in one) were unrelated to farmer's lung. Six patients refused to take part in the clinical investigations and two patients were excluded due to lack of a suitable control farmer. Thus the present analyses included 89 FL patients.

All FL patients were diagnosed in Kuopio University Hospital in eastern Finland between 1977 and 1982. In all patients, this was their first diagnosed episode of farmer's lung and all fulfilled the diagnostic criteria for farmer's lung presented by TERHO [9].

Twenty nine of the 89 FL patients included in the present study had participated during the acute stage of farmer's lung in a double-blind, placebo-controlled study, in which the effect of corticosteroid treatment on the recovery of pulmonary function during a $5 \mathrm{yr}$ followup was evaluated [10]. Sixteen patients were given prednisolone treatment for 8 weeks and 13 patients received an 8 week placebo treatment.

Clinical examinations took place between August 1993 and April 1994. When the present study was performed, there had been a mean interval of 14 yrs (range 11-16 yrs) after the initial diagnosis of the farmer's lung disease.

Control farmers were selected among 2,424 participants to a questionnaire survey assessing farmers' health 
performed in 1979 [11], to which all farmers from three municipalities in Kuopio University Hospital district were invited. More than $94 \%$ of those invited participated in the study in 1979. The three municipalities are geographically and socioeconomically representative of the whole Kuopio University Hospital district. Since all FL patients had cattle tending as their main farm operation, only control farmers with the same occupation in 1979 were selected. Farmer's lung patients and control farmers were divided into strata on the basis of age ( 5 yr age categories), sex, and smoking habits at the time of the diagnosis or in the 1979 survey (lifetime nonsmoker, exsmoker or current smoker). Within each stratum, four times more control farmers were randomly selected than FL patients in that stratum, and they were sent a questionnaire. Three hundred and twenty one of $379(85 \%)$ farmers returned the questionnaires. One control farmer to each FL patient was invited to a clinical examination. If a control farmer refused, a new control farmer from the same stratum was selected. Eighty six of the 138 control farmers invited (62\%) participated in the clinical examinations. Two control farmers were, however, excluded from the analyses, one because her smoking habit was wrongly coded in the initial study in 1979 and one because she herself had suffered from FL 3 yrs earlier. Thus, 84 control farmers were included in the present analyses.

\section{Questionnaire}

All FL patients and control farmers filled in a premailed, self-administered questionnaire of current and previous farming activities, respiratory symptoms, smoking habits, and clinical diseases. The same doctor (RE$\mathrm{P})$ made a clinical examination, and reviewed and completed, if necessary, the premailed questionnaire with the farmer. Medical files were studied for chronic diseases and recurrences of FL. Subjects were considered to have current asthma if the diagnosis of asthma had been confirmed by a physician, and if symptoms of asthma were present during the preceding 12 months. The respondent was classified as having chronic bronchitis if she/he had coughed up phlegm on most days for at least 3 months per year during at least 2 yrs. Subjects who fulfilled the criteria of chronic bronchitis but also had asthma were not considered to have chronic bronchitis.

\section{Pulmonary function tests}

All pulmonary function measurements were conducted by the same trained nurse. Height and weight were measured. Spirometry (SensorMedics 2200; SensorMedics, Yorba Linda, CA, USA) was performed according to American Thoracic Society (ATS) guidelines [12]. At least three acceptable expiratory manoeuvres were performed and the largest forced vital capacity (FVC) and forced expiratory volume in one second (FEV1) were recorded. From the curve of largest sum of FVC and FEV1, maximum expiratory flow at $50 \%$ of vital capacity (MEF50) was selected. Two slow inspiratory vital capacities (IVC) were then measured. The largest vital capacity (VC) from FVC and IVC measurements was taken as the result. The two largest VC differed by less than $5 \%$ or $100 \mathrm{~mL}$ in $98 \%$ of the examinations and the two largest FEV1 by less than $5 \%$ or $100 \mathrm{~mL}$ in $97 \%$ of the examinations. The reference values were according to VILJANEN et al. [13].

Measurement of the transfer factor of the lung for carbon monoxide ( $T$ L,CO) (SensorMedics 2200; SensorMedics, Yorba Linda, CA, USA) was conducted using a single-breath technique [14]. At least two acceptable manoeuvres were performed. The mean of those two $T \mathrm{~L}, \mathrm{CO}$ measurements was taken as the result. The two largest $T \mathrm{~L}, \mathrm{CO}$ differed by less than $0.7 \mathrm{mmol} \cdot \mathrm{min}^{-1} \cdot \mathrm{kPa}^{-1}$ in $99 \%$ of the measurements. The reference values were according to the European Coal and Steel Community (ECSC) [15].

The study protocol was approved by the Ethics Committee of Kuopio University Hospital.

\section{Statistical analysis}

Comparisons of continuous variables were made using analyses of covariance and of categorical variables using logistic regression. All comparisons of pulmonary function were adjusted for sex, smoking at the time of diagnosis or in 1979 in three categories, and age and height as continuous variables. Other comparisons were unadjusted. Adding weight to pulmonary function models did not change the results and, therefore, weight was not included in the final models. All pulmonary function analyses were also repeated using conditional logistic regression models, where the case status was used as the dependent variable [16]. The results from these analyses were practically identical to those presented. Statistical analyses were performed using the Statistical Products and Services Solutions (SPSS) software package.

\section{Results}

The main characteristics of the FL patients and control farmers are presented in table 1. After the initial Table 1. - Main characteristics of the farmer's lung (FL) patients and the control farmers

\begin{tabular}{|c|c|c|}
\hline & $\begin{array}{c}\text { FL } \\
\text { patients }\end{array}$ & $\begin{array}{l}\text { Control } \\
\text { farmers }\end{array}$ \\
\hline Subjects $\mathrm{n}$ & 89 & 84 \\
\hline Female $\mathrm{n}$ & $69(78)$ & $64(76)$ \\
\hline Retired $\mathrm{n}$ & $60(67)$ & $53(63)$ \\
\hline \multicolumn{3}{|l|}{ Smoking habits $\mathrm{n}^{\#}$} \\
\hline Nonsmokers & $73(82)$ & $68(81)$ \\
\hline Exsmokers & $7(8)$ & $7(8)$ \\
\hline Smokers & $9(10)$ & $9(11)$ \\
\hline \multicolumn{3}{|l|}{ Main farm operation $\mathrm{n}^{\#}$} \\
\hline Dairy cattle & $86(97)$ & $82(98)$ \\
\hline Beef cattle & $3(3)$ & $2(2)$ \\
\hline Age yrs & $60 \pm 9$ & $60 \pm 8$ \\
\hline Height $\mathrm{cm}$ & $161 \pm 9$ & $162 \pm 8$ \\
\hline Weight $\mathrm{kg}$ & $72 \pm 12$ & $77 \pm 15^{*}$ \\
\hline Dairy cattle $n^{\#}$ & $10.8 \pm 5.7$ & $9.2 \pm 3.8^{*}$ \\
\hline Area under cultivation acres\# & $16.3 \pm 8.0$ & $14.2 \pm 7.2$ \\
\hline
\end{tabular}

Values are presented as absolute number and percentage in parenthesis, or as mean \pm SD. \#: at the time of the diagnosis of FL (1977-1982) among FL patients and in 1979 among control farmers. *: $\mathrm{p}<0.05$, compared to FL patients. 
diagnosis of FL, five of the nine smoking FL patients had stopped smoking. In contrast, only one of the nine smoking control farmers had stopped smoking after 1979. FL patients weighed on average $5 \mathrm{~kg}$ less than control farmers.

At the time of the present examination, $39 \%$ of the FL patients still worked regularly in the cow house, $4 \%$ worked occasionally, and $57 \%$ did not participate in farmwork. The respective figures for control farmers were 38, 7 and $55 \%$. Twenty four per cent of the FL patients and $28 \%$ of the control farmers had changed their main farm operation, most often from dairy cattle to beef cattle. The difference in the mean number of dairy cattle (table 1) disappeared during the follow-up. At the time of follow-up, it was 11.7 (5.5) in control farmers and 12.5 (6.5) in FL patients. The slight difference in the mean area under cultivation remained during the whole follow-up. Fifty five per cent of FL patients but only $12 \%$ of control farmers had used a half-type or powered dust helmet respirator.

The transfer factor of the lung for carbon monoxide was on average $12 \%$ lower in FL patients compared to control farmers (table 2). Restricting the analyses to only lifetime nonsmokers, the 73 nonsmoking FL patients had, as a mean, a $14 \%$ lower TL,CO $(\mathrm{p}<0.001)$ than the 68 nonsmoking control farmers. This difference was $15 \%$ $(\mathrm{p}<0.001)$ among the female farmers and $9 \%(\mathrm{p}=0.18)$ among male farmers.

In spirometry, FL patients tended to have lower mean values of MEF50 and FEV1/VC (table 2). The proportion of persons with airway obstruction $(\mathrm{FEV} 1 / \mathrm{VC}$ less than $88 \%$ of predicted) was significantly larger in FL patients $(33 \%)$ than in control farmers $(17 \%) \quad(p=0.02)$.

There were no statistically significant differences in present pulmonary function in FL patients with and without steroid treatment during the acute stage of FL. In the placebo group $(n=13)$ of this double-blind, placebocontrolled study, the mean VC was $99 \%$ pred, mean FEV1 $91 \%$ pred, mean MEF50 68\% pred, mean FEV1/VC $92 \%$ pred and mean TL,CO $99 \%$ pred. The values in the steroid treatment group $(\mathrm{n}=16)$ were 106, 98, 71, 92 and $96 \%$ pred, respectively.

Table 2. - Spirometry and pulmonary transfer factor in farmer's lung (FL) patients and control farmers

\begin{tabular}{|c|c|c|c|}
\hline & $\begin{array}{c}\text { FL } \\
\text { patients } \\
(\mathrm{n}=89)\end{array}$ & $\begin{array}{c}\text { Control } \\
\text { farmers } \\
(n=84)\end{array}$ & p-value* \\
\hline $\begin{array}{ll}\text { VC } & \text { L } \\
\% \text { pred }\end{array}$ & $\begin{array}{c}3.45 \pm 0.86 \\
102 \pm 14\end{array}$ & $\begin{array}{c}3.48 \pm 0.84 \\
100 \pm 14\end{array}$ & 0.53 \\
\hline \begin{tabular}{ll} 
FEV1 & \multicolumn{1}{l}{} \\
& $\%$ pred
\end{tabular} & $\begin{array}{c}2.46 \pm 0.64 \\
93 \pm 14\end{array}$ & $\begin{array}{l}2.55 \pm 0.67 \\
94 \pm 15\end{array}$ & 0.60 \\
\hline $\begin{aligned} \mathrm{FEV}_{1} / \mathrm{VC} & \% \\
& \% \text { pred }\end{aligned}$ & $\begin{array}{l}72 \pm 7 \\
91 \pm 8\end{array}$ & $\begin{array}{l}73 \pm 7 \\
94 \pm 9\end{array}$ & 0.12 \\
\hline $\begin{array}{ll}\text { MEF50 } & \mathrm{L} \cdot \mathrm{s}^{-1} \\
& \% \text { pred }\end{array}$ & $\begin{array}{l}2.71 \pm 1.16 \\
70 \pm 26\end{array}$ & $\begin{array}{l}3.06 \pm 1.25 \\
77 \pm 27\end{array}$ & 0.08 \\
\hline $\begin{array}{ll}T \mathrm{~L}, \mathrm{CO} & \mathrm{mmol} \cdot \mathrm{min}^{-1} \cdot \mathrm{kPa}^{-1} \\
& \% \text { pred }\end{array}$ & $\begin{array}{c}7.46 \pm 1.98 \\
98 \pm 19\end{array}$ & $\begin{array}{l}8.61 \pm 1.89 \\
110 \pm 16\end{array}$ & $<0.001$ \\
\hline
\end{tabular}

Values are presented as mean \pm SD. *: adjusting for age, sex, smoking and height using analysis of covariance; $*$ : FL patients $(n=88)$, control farmers $(n=83)$. VC: vital capacity; \% pred: percentage of predicted value; FEV1: forced expiratory volume in one second; MEF50: maximum expiratory flow at 50\% of vital capacity; TL,CO: transfer factor of the lung for carbon monoxide.
Fifty three FL patients (60\%) had experienced only one diagnosed episode of FL. Thirty six patients (40\%) had experienced recurrent episodes of the disease: one recurrence (26 patients); two recurrences (eight); three recurrences (one); and four recurrences (one). The first recurrence occurred during the first year after the initial diagnosed episode of FL in 13 patients, after 1-5 yrs in 12 , and after more than 5 yrs in 11 patients. The interval between the last recurrence and the present study was on average 8 yrs.

Patients with recurrent episodes of FL had more pronounced impairment in $T \mathrm{~L}$, CO than those who had experienced only a single diagnosed episode of the disease (table 3). No significant difference in this respect was observed in ventilatory function.

Diagnosed asthma was present in $14(16 \%)$ FL patients and in $12(14 \%)$ control farmers. In all of the FL patients, asthma had been diagnosed after the diagnosis of FL. In one FL patient, the diagnosis of asthma was established during the clinical evaluation of this study. The mean time between the first episode of FL and the diagnosis of asthma was 7 yrs (range 1-16 yrs). In four of the 12 control farmers with asthma, the diagnosis was established during the clinical evaluation of this study. The occurrence of chronic bronchitis was $23 \%$ in the FL patients and $19 \%$ in the control farmers. The great majority of them were lifetime nonsmokers in both groups (88 and 79\%).

The mean VC in asthmatic FL patients was $97 \%$ pred, mean FEV1 $85 \%$ pred, mean MEF50 55\% pred, mean FEV1/VC $88 \%$ pred and mean TL,CO $102 \%$ pred. The figures among asthmatics in control farmers were 96, $81,46,83$ and $111 \%$ pred, respectively. Thus, airway obstruction was on average more severe in asthmatic control farmers than in asthmatic FL patients. After exclusion of all subjects with asthma from the analyses, the differences between the FL patients and the control farmers in mean $\mathrm{FEV} 1 / \mathrm{VC}$ (92 versus $95 \%$; $\mathrm{p}=0.007$ ) and the mean MEF50 (72 versus $82 \%$; $\mathrm{p}=0.02$ ) was more pronounced and statistically significant. The difference in the mean $T \mathrm{~L}, \mathrm{CO}$ remained at $14 \%$.

Table 3. - Spirometry and pulmonary transfer factor in farmer's lung (FL) patients with a single episode of the disease and in patients with one or more recurrences

\begin{tabular}{|c|c|c|c|}
\hline & $\begin{array}{l}\text { Single } \\
\text { episode }\end{array}$ & $\begin{array}{l}\text { Recurrent } \\
\text { episode(s) }\end{array}$ & p-value* \\
\hline Patients $\mathrm{n}$ & 53 & 36 & \\
\hline Sex $\mathrm{M} / \mathrm{F}$ & $15 / 38$ & $5 / 31$ & \\
\hline Age yrs & $60 \pm 9$ & $60 \pm 8$ & \\
\hline Nonsmokers $\mathrm{n}$ & 43 & 30 & \\
\hline Smokers $^{\dagger} \mathrm{n}$ & 10 & 6 & \\
\hline $\begin{array}{l}\mathrm{VC} \quad \mathrm{L} \\
\quad \% \text { pred }\end{array}$ & $\begin{array}{l}3.57 \pm 0.94 \\
102 \pm 13\end{array}$ & $\begin{array}{l}3.27 \pm 0.70 \\
102 \pm 16\end{array}$ & 0.67 \\
\hline $\begin{array}{ll}\text { FEV1 } & \mathrm{L} \\
& \% \text { pred }\end{array}$ & $\begin{array}{l}2.54 \pm 0.73 \\
92 \pm 14\end{array}$ & $\begin{array}{l}2.35 \pm 0.48 \\
94 \pm 15\end{array}$ & 0.75 \\
\hline $\begin{array}{ll}\text { MEF50 } & \mathrm{L} \cdot \mathrm{s}^{-1} \\
& \% \text { pred }\end{array}$ & $\begin{array}{c}2.73 \pm 1.32 \\
68 \pm 28\end{array}$ & $\begin{array}{c}2.69 \pm 0.90 \\
72 \pm 24\end{array}$ & 0.31 \\
\hline $\begin{aligned} T \mathrm{~L}, \mathrm{CO}^{\ddagger} & \mathrm{mmol}_{\%} \cdot \mathrm{min}^{-1} \cdot \mathrm{kPa}^{-1} \\
& \text { pred }\end{aligned}$ & $\begin{array}{l}7.95 \pm 2.01 \\
102 \pm 18\end{array}$ & $\begin{array}{c}6.71 \pm 1.70 \\
90 \pm 18\end{array}$ & 0.02 \\
\hline
\end{tabular}

Values are presented as mean \pm SD. $\dagger$ : including current and exsmokers; $¥: \mathrm{n}=88$; *: adjusting for age, sex, smoking and height using analysis of covariance. For definitions see legend to table 2 . 


\section{Discussion}

The FL patients who had experienced an initial episode of FL on average 14 yrs prior to this follow-up, had a significantly lower pulmonary transfer factor than control farmers. After a single episode of FL, the difference was of the order of $10 \%$ and after two or more episodes it had increased to about $20 \%$.

Patients with FL tended to have lower mean MEF50, and more often had airway obstruction than control farmers. The difference in FEV1/VC between the patients and the controls reached statistical significance after excluding all asthmatics from the analyses, since control farmers with asthma had lower FEV1/VC than asthmatic FL patients, perhaps because their asthma was more often undiagnosed. Thus, the airway obstruction observed among FL patients was not explained by the presence of overt asthma. Although it has been suggested that FL may also lead to a restrictive ventilatory function defect [17], no significant difference in mean VC between the study groups was found in the present study.

A control group is essential when studying pulmonary disorders in farmers. In general, airway obstruction and chronic bronchitis has been shown to be associated with working on a farm [5-8]. Farmers with pulmonary problems may also stop farming. Therefore, the results from clinical series are difficult to interpret. In the present study, we were fortunate to be able to select controls from a survey performed close to the same period when the FL patients were diagnosed. Therefore, the cases and the controls were comparable at the beginning of the follow-up, which reduces the possibilities for bias. Moreover, the groups were representative in the extent to which they spent time working in the cow house.

The present results may, however, underestimate the true difference in spirometric values and in the risk of chronic bronchitis due to FL. FL patients used personal dust respirators significantly more often and a greater proportion of them had stopped smoking, both of which may protect from a decline in pulmonary function. Also, there is a suggestion that control farmers with respiratory disorders were more willing to participate in the clinical examination of the present study. The prevalence of chronic bronchitis was clearly higher (19\%) among those control farmers that took part in the clinical examinations than among those control farmers $(10 \%)$ that only returned the questionnaire [18].

In previous uncontrolled follow-up studies, impaired $T \mathrm{~L}, \mathrm{CO}$ has also been reported to be the most common long-term sequela of FL [2, 3, 19, 20]. In contrast to many previous studies, the present study population was predominantly female, although the impairment of $T \mathrm{~L}, \mathrm{CO}$ was similar both in males and females. Improvement of $T \mathrm{~L}, \mathrm{CO}$ has been shown to occur up to 2 yrs after the diagnosis of FL [1], thus the findings from the present study probably represent permanent damage caused by FL. Impaired $T \mathrm{~L}, \mathrm{CO}$ has usually been thought to be caused by interstitial pulmonary fibrosis [3, 17]. However, in a $6 \mathrm{yr}$ follow-up study of $33 \mathrm{FL}$ patients, which included high-resolution computed tomography (HRCT), emphysema was found to be much more common than fibrosis [4]. Thus, it is also possible that lowered pul- monary transfer factor among FL patients may be caused by emphysema or fibrosis or both.

In other follow-up studies, years after the diagnosis of FL, an obstructive ventilatory function impairment has been reported more commonly than a restrictive defect $[1,2,4]$. Bronchiolitis is inherent to the histological picture of FL [21-25], and may provide a morphological explanation for the development of airway obstruction [4, 17]. Obstructive and emphysematous changes were considered to be the most prevalent functional and structural abnormalities resulting from FL in the study by LALANCETTE et al. [4], which also included HRCT. Thus, airway obstruction is also probably an important long-term sequela of FL.

In the present study, about every fifth farmer had chronic bronchitis both among FL patients and control farmers. However, the high proportion of control farmers with chronic bronchitis was possibly due to selfselection bias, as discussed previously. Several previous studies have suggested that FL causes chronic bronchitis [2, 3], and a close link between chronic bronchitis and FL has been reported in two different epidemiological studies among farmers from Doubs, France [26, 27]. Nonsmoking "healthy" dairy farmers have also been shown to have an excess risk of chronic bronchitis, and it has been hypothesized that chronic bronchitis in dairy farmers may be of immunoallergic origin, in which host factors play an important role [28]. It seems probable that FL is also a risk factor, besides exposure to organic dusts, for the development of chronic bronchitis.

The prevalence of asthma (about 15\%) was high both in patients with FL and in control farmers. Asthma has rarely been reported in patients at the time of the diagnosis of FL [1, 3, 29, 30], but, according to the present study and an earlier study by CUTHBERT and GORDON [31], asthma seems to not be uncommon years after suffering from FL.

In conclusion, an impaired pulmonary transfer factor seems to be the most prominent pulmonary functional defect caused by farmer's lung. In this follow-up, which took place on average 14 yrs after the initial diagnosis of farmer's lung, the mean transfer factor of the lungs for carbon monoxide was $12 \%$ lower in farmer's lung patients compared to control farmers. Patients with recurrent episodes of farmer's lung had an even larger reduction in transfer factor of the lungs for carbon monoxide. In addition, a tendency for airway obstruction was found in farmer's lung patients compared to control farmers. The present results highlight the importance both of primary and secondary prevention of farmer's lung.

\section{References}

1. Kokkarinen JI, Tukiainen HO, Terho EO. Recovery of pulmonary function in farmer's lung: a five year followup study. Am Rev Respir Dis 1993; 147: 793-796.

2. Braun SH, doPico GA, Tsiatis A, Horvarth E, Dickie HA, Rankin J. Farmer's lung disease: long-term clinical and physiologic outcome. Am Rev Respir Dis 1979; 119: 185-191.

3. Mönkäre S, Haahtela T. Farmer's lung: a 5 year followup of eighty six patients. Clin Allergy 1987; 17: 143151. 
4. Lalancette M, Carrier G, Laviolette M, et al. Farmer's lung: long-term outcome and lack of predictive value of bronchoalveolar lavage fibrosing factors. Am Rev Respir Dis 1993; 148: 216-221.

5. Babbot FL, Gump DW, Sylwester DL, MacPherson BV, Holly RC. Respiratory symptoms and lung function in a sample of Vermont dairymen and industrial workers. Am J Public Health 1980; 70: 241-245.

6. Heller RF, Hayward DM, Farebrother MTB. Lung function of farmers in England and Wales. Thorax 1986; 41: 117-121.

7. Dosman JA, Graham BL, Hall D, Loon PV, Bhasin P, Froh F. Respiratory symptoms and pulmonary function in farmers. J Occup Med 1987; 29: 38-42.

8. Dalphin JC, Bildstein F, Pernet D, Dubiez A, Depierre A. Prevalence of chronic bronchitis and respiratory function in a group of dairy farmers in the French Doubs province. Chest 1989; 95: 1244-1247.

9. Terho EO. Diagnostic criteria for farmer's lung disease. Am J Ind Med 1986; 10: 329.

10. Kokkarinen JI, Tukiainen HO, Terho EO. Effect of corticosteroid treatment on the recovery of pulmonary function in farmer's lung. Am Rev Respir Dis 1992; 145: 3-5.

11. Vohlonen I, Husman K, Kalimo E, et al. Farmers' work and health 1979. Publications of the Social Insurance Institution, Finland, 1981; A:17, Helsinki (in Finnish).

12. American Thoracic Society. Standardization of spirometry: 1987 update. Am Rev Respir Dis 1987; 136: 1285-1298.

13. Viljanen AA, Halttunen PK, Kreus K-E, Viljanen BC. Spirometric studies in nonsmoking healthy adults. Scand J Clin Lab Invest 1982; 42 (Suppl. 159): 5-20.

14. American Thoracic Society. Single-breath carbon monoxide diffusing capacity (transfer factor): recommendations for standard technique. Am Rev Respir Dis 1987; 136: 1299-1307.

15. Cotes JE, Chinn DJ, Quanjer PhH, Roca J, Yernault JC. Standardization of the measurement of transfer factor (diffusing capacity). Eur J Respir Dis 1993; 6 (Suppl. 16): 41-52.

16. Breslow NE, Day NE. Statistical methods in cancer research. Volume 1. The analysis of case-control studies. IARC Scientific Publications No. 32. Lyon, 1980.

17. Hapke EJ, Seal RME, Thomas GO, Hayes M, Meek JC. Farmer's lung: a clinical, radiographic, functional and serological correlation of acute and chronic stages. Thorax 1968; 23: 451-468.

18. Erkinjuntti-Pekkanen R. Long-term outcome of farmer's lung: pulmonary function, serology, radiologic findings on HRCT, and socioeconomic outcome of FL patients and matched controls. Doctoral dissertation. Kuopio University Publications D, Medical Sciences 111, 1996.

19. Barbee RA, Callies Q, Dickie HA, Rankin J. The longterm prognosis in farmer's lung. Am Rev Respir Dis 1966; 97: 223-231.

20. Cormier Y, Bélanger J. Long-term physiologic outcome after acute farmer's lung. Chest 1985; 87: 796-800.

21. Emanuel DA, Wenzel FJ, Bowerman CI, Lawton BR. Farmer's lung: clinical, pathologic and immunologic study of twenty four patients. Am J Med 1964; 37 : 392-401.

22. Seal RME, Hapke EJ, Thomas GO, Meek JC, Hayes M. The pathology of the acute and chronic stages of farmer's lung. Thorax 1968; 23: 469-489.

23. Reyes CN, Wenzel FJ, Lawton BR, Emanuel DA. The pulmonary pathology of farmer's lung disease. Chest 1982; 81: 142-146.

24. Tukiainen P, Taskinen E, Korhola O, Valle M. Farmer's lung: needle biopsy findings and pulmonary function. Eur J Respir Dis 1980; 61: 3-11.

25. Sutinen S, Reijula K, Huhti E, Kärköla P. Extrinsic allergic bronchioloalveolitis: serology and biopsy findings. Eur J Respir Dis 1983; 64: 271-282.

26. Depierre A, Dalphin JC, Pernet D, Dubiez A, Faucompré C, Breton JL. Epidemiological study of farmer's lung in five districts of the French Doubs province. Thorax 1988; 43: 429-435.

27. Dalphin JC, Debieuvre D, Pernet D, et al. Prevalence and risk factors for chronic bronchitis and farmer's lung in French dairy farmers. Br J Ind Med 1993; 50: 941-944.

28. Dalphin JC, Pernet D, Dubiez A, Debieuvre D, Allemand $\mathrm{H}$, Depierre A. Etiologic factors of chronic bronchitis in dairy farmers: case-control study in the Doubs region of France. Chest 1993; 103: 417-421.

29. Pepys J. Hypersensitivity diseases of the lungs due to fungi and organic dusts. Monogr Allergy 1069; 4: 1-147.

30. Karr RM, Kohler PF, Salvaggio JE. Hypersensitivity pneumonitis and extrinsic asthma; an unusual association. Chest 1978; 74: 98-102.

31. Cuthbert OD, Gordon AF. Ten year follow-up of farmers with farmer's lung. Br J Ind Med 1982; 40: 173-176. 